\title{
HYBRID MODEL OF WIND SPEED PREDICTION IN SHORT TIME RANGE USING WRF AND ARTIFICIAL NEURAL NETWORKS
}

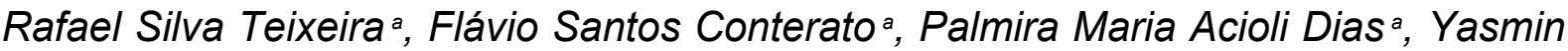 \\ Kaore Lago Kitagawa ${ }^{b}$, Davidson Martins Moreira a, Erick Giovani Sperandio \\ Nascimento $^{a}$
}

a, SENAI CIMATEC University Center, Brazil

', Federal University of Espirito Santo, Brazil

\begin{abstract}
This paper applies a hybrid model of wind speed forecasting in short-term to the watershed basin of Paranapanema, Brazil, as strategy to decrease computational demand typically observed in exclusively WRF-based predictions, while deals with an also common lack of measured atmospheric variables in greater spatial and time frame resolution. The model uses adjusted variables from real data simulated WRF outputs for the target area as input of a MultiLayer Perceptron (MLP) Neural Network (ANN) configured with Feed-forward Backpropagation algorithm, tested with different combinations of parameters. The association here proposed aims to match the best of both methods to mitigate each other's typical issues and provide, supported by future works, even better accurate results also for other atmospheric elements.
\end{abstract}

Keywords: ANN; Artificial Intelligence; Atmospheric Science; MLP; WRF.

\section{MODELO HÍBRIDO DE PREVISÃO DE VELOCIDADE DO VENTO A CURTO PRAZO UTILIZANDO WRF E REDES NEURAIS ARTIFICIAIS}

Resumo: O modelo híbrido aqui aplicado à bacia hidrográfica do Paranapanema, Brasil, sugere a diminuição da demanda computacional tipicamente observada em previsões baseadas exclusivamente em WRF; e lida com a também comum baixa oferta de dados atmosféricos em maior resolução espacial e temporal. Variáveis ajustadas, oriundas de simulações de dados reais no WRF para a área alvo, são utilizadas como dados de entrada de uma Rede Neural (RNA) MultiLayer Perceptron (MLP) com algoritmo Feed-forward Backpropagation (para diferentes combinações de parâmetros). Esta associação visa combinar o melhor dos dois métodos para mitigar os problemas típicos um do outro e fornecer, apoiado por trabalhos futuros, resultados ainda melhores e precisos também para outros elementos atmosféricos.

Palavras-chave: Ciência Atmosférica; Inteligência Artificial; MLP; RNA; WRF. 


\section{INTRODUCTION}

The efforts regarding atmospheric studies reflect an increasing awareness that environmental conditions and anthropogenic elements are both connected in a cause and consequence circle. In general, the development of new techniques is not singlebeneficent neither restricted to one or another area's motivation. An example of that, Artificial Intelligence $(\mathrm{Al})$ has implemented many traditional methods in the last few years. This kind of combination, between old and new, economic and environmentally engaged, has frequently provided not only more accurate results but also more efficient ways to obtain them. That said, this paper can be placed in line with the current trend while proposing the combined use of the Weather Research and Forecasting program (WRF) and Al to predict wind speed in short range and scale. The hybrid method here suggested shows itself at this point as a reasonable alternative while demanding less computational capacity and abording an aspect shared by both: economic and environmental matters. As a potential renewable energy source, the relevance attributed to the winds analysis emerges from environmental public policies in the 90's and goes further on in the power industry, as a profitable way to obtain clean energy and help society achieving sustainability in its energy and emissions matrix. The benefits of wind power industry implementation have local and global impacts (environmental and economically) [1-3].

Widely applied to atmospheric researches (academic and commercially), the WRF model makes use of global and synoptic-scale data, i.e. from the Global Forecast System (GFS) and the North American Mesoscale Model (NAM, former ETA) as simulation input to deliver numerical weather forecasting. Although the WRF system operates several transformation-steps over those inputs data, as a mesoscale model, WRF is also limited inasmuch as demanded of a greater resolution. The atmospheric processes within the planetary boundary (PBL) have more influence over the atmospheric dynamic at smaller time and space scales, which (when in use of WRF for these cases) requires different physical parameterizations that usually are determined empirically to apply more specific domain characteristics. The fact that WRF does not show the same practical applicability supporting analysis when the scale becomes shorter (in time and space) highlights the opportunity of filling this gap with new proposals $[4,5]$.

Techniques of deep learning are becoming more often applied to climate and weather analysis, air quality forecasting, and even for renewable energy matters, such as solar and wind power feasibility studies. Beyond the idea of enhancing the literature with more analysis regarding this still innovative use of the Al, the strategy of keeping the partial use of WRF in a hybrid model is to deal with a gap, not yet covered by the state-of-arts, which is the shortage of reliable and specific local data. Overcoming the WRF model completely turns to be more complex when the simulation inputs are limited to global and synoptic-scale data, which are largely available but mostly in lower resolution (considering local analysis goals). The implementation of an Al model, following the WRF application over the quality of input data (originally from global-scale widespread sources), emerges as an innovative alternative to deal with another common issue for atmospheric and environmental analysis: the high computational demand by models as WRF itself. Both methods combined, should increase efficiency at smaller-scaled simulations, demanding less of computational use and bypass 
eventual lack of data. Briefly described, this work proposes the development of an AI model that uses WRF output results as spin data for the prediction of wind speed $[5,6]$.

\section{METHODOLOGY}

The framework was based on four main stages: (1) model domain definition, (2) simulations with WRF model, (3) Artificial Neural Network (ANN) construction and training, and (4) the data exploratory analysis - considered as an interstitial recurrent and inherent effort for the quality of the other three. The domain area (represented at Figure 1) and simulation period selected for this work have been targeted of previous study-cases developed at the Manufacturing and Technology Integrated Campus (SENAI CIMATEC): the watershed basin of Paranapanema reaches 247 cities located between the Brazilian states of São Paulo and Paraná. The area houses a relevant share of national economic activities, naturally influenced by atmospheric conditions and has several weather stations from the Brazilian National Institute of Meteorology (INMET). The point in this definition is to get hold of a validated configuration package for WRF (as a first step) while focusing on the adjustment of the Al model to the wind data behavior. The georeferenced information reaching the ANN input layer comes originally from the Global Data Assimilation System Model (GDAS) after a transformation process on WRF considering specificities of the domain through the configuration set shown in Table 1. The Advanced Research WRF (ARW), typically applied to real data cases [4], has been selected, so as further domain configurations.

Figure 1. Paranapanema river basin, WRF domains and INMET weather stations

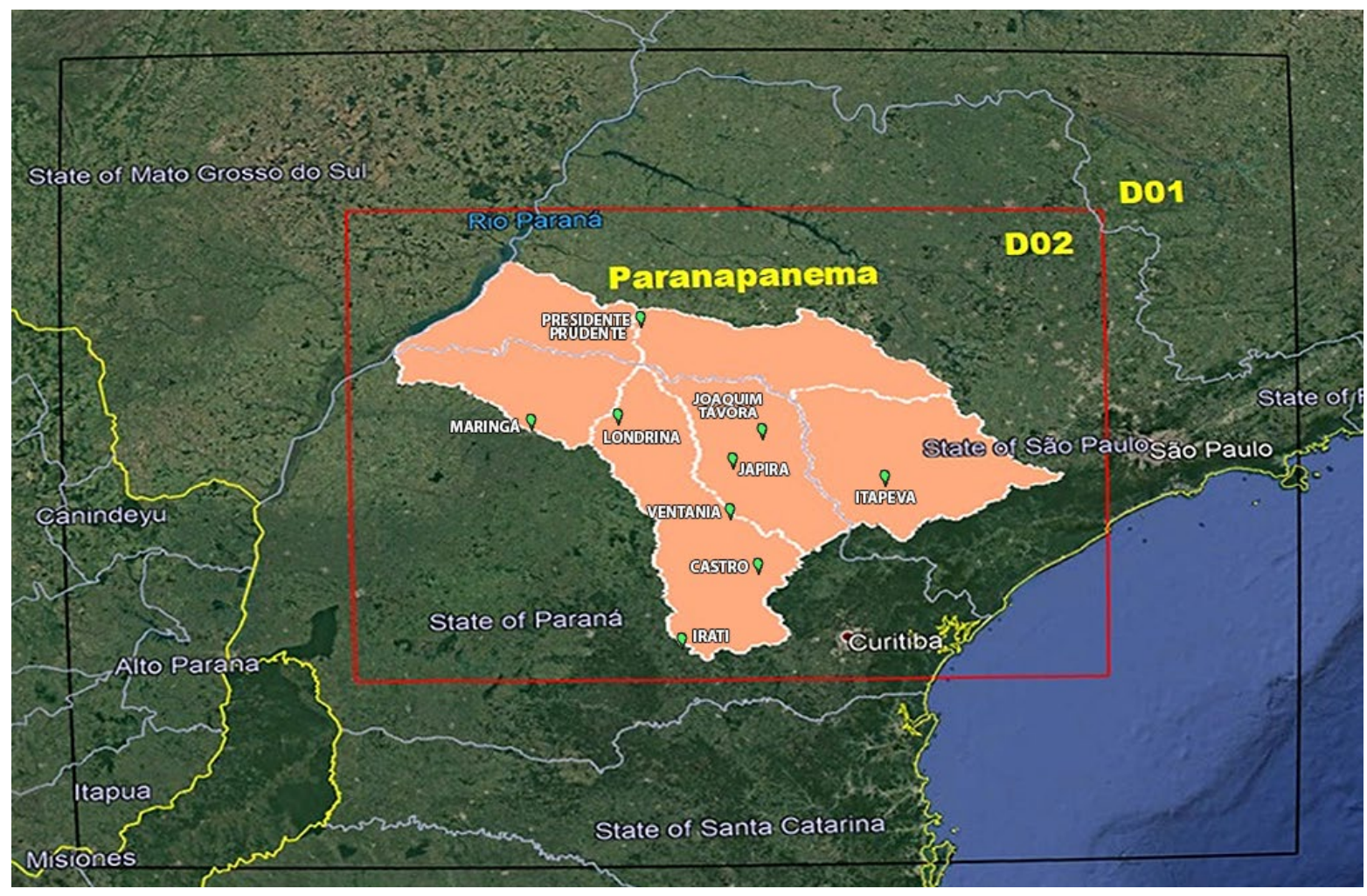


Table 1. Physical and Domain Parameterization for WRF

\begin{tabular}{|c|c|c|c|}
\hline Parameter & \multicolumn{3}{|c|}{ Simulated } \\
\hline Microphysical Properties & \multicolumn{3}{|c|}{ Eta } \\
\hline Cumulus & \multicolumn{3}{|c|}{ Betts-Miller-Janjić } \\
\hline Long and Short-wave Radiation & \multicolumn{3}{|c|}{$R R T M G$} \\
\hline Surface / Planetary Boundary Layer & \multicolumn{3}{|c|}{ MYNN / MYNN2.5 } \\
\hline Surface & \multicolumn{3}{|c|}{ Noah Land-Surface } \\
\hline Aerosol & \multicolumn{3}{|c|}{ Without aerosol } \\
\hline Grid Resolution (D01 | D02 | Cropped) & $9 \mathrm{~km}$ & $3 \mathrm{~km}$ & $3 \mathrm{~km}$ \\
\hline Number of Cells (Vertical x Horizontal) & $100 \times 118$ & $189 \times 246$ & $183 \times 240$ \\
\hline Domain Dimensions (km) & $900 \times 1062$ & $567 \times 738$ & $549 \times 720$ \\
\hline Simulated Period (2017) | Spin-up 72h & \multicolumn{2}{|c|}{$28 / 04-16 / 06$} & 01/05-15/06 \\
\hline
\end{tabular}

For the analysis of Al model, only WRF outputs from the inner domain (D02) were considered due to its better resolution. After adjustment respecting a minimum of 48h spin-up and 6 border lanes crop [4], the amount of 1,104 hourly samples per cell multiplied by 43,920 grid-cells available provided $48,487,680$ variously behaved input samples of each relevant meteorological variable, that are listed in Table 2 . The whole process from WRF output on, including exploratory analysis and ANN working process, has been developed in programming language Python (using the software Anaconda and Jupyter Notebook).

Table 2. WRF Outputs and ANN Input Variables

\begin{tabular}{|l|c|}
\hline WRF Output & Description \\
\hline U10 / V10 & x / y-wind component (at 10m) \\
\hline LU_INDEX & land use category \\
\hline HGT / PBLH & terrain / PBL height \\
\hline XTIME & minutes since simulation start \\
\hline XLAT / XLONG & latitude / longitude (south / west is negative) \\
\hline LANDMASK & land mask (1 for land, 0 for water) \\
\hline T2 & temperature (at 2 m) \\
\hline
\end{tabular}




\begin{tabular}{|l|c|}
\hline PSFC & surface pressure \\
\hline Q2 & water vapor mixing ratio at $(2 \mathrm{~m})$ \\
\hline RAINNC & accumulated total grid scale precipitation \\
\hline SWDOWN & downward short-wave flux at ground surface \\
\hline
\end{tabular}

Other two variables besides those on Table 2 have been also used as input for the ANN. Both came from the vector sum between U10 and V10. One, the target itself, represents the magnitude of the resultant wind speed, while the other considers only the direction translated to an angular coordinate system $\left(0-359^{\circ}\right)$. Once the wind speed magnitude was defined as prediction target in this study-case, a systematic review revealed the Multilayer Perceptron (MLP) as an efficient ANN type for this task in short-range conditions [6-9]. Applied to the MLP, the Feed-forward Backpropagation algorithm has also improved the model's efficiency [10-13]. Table 3 brings the common parts between configuration sets used. Other parameters for the MLP architecture are more flexibly determined and should be adjusted along the building process. A simple input-hidden-output 3-Layer network structure, with 16 neurons on the two first and 1 neuron on the output layer, was used to choose between three activation functions. The configuration with a better performance at this first test has been chosen for following architecture validations. From those configurations explored, the best ones (classified by number of layers) were selected to be presented in the Results section.

Table 3. MLP Explored Parameters

\begin{tabular}{|l|c|}
\hline \multicolumn{1}{|c|}{ Parameter } & Description \\
\hline ANN Type & Multilayer Perceptron \\
\hline Algorithm & Feed-forward Backpropagation \\
\hline Input Variables / Target & Adjusted WRF Outputs / Wind speed \\
\hline Hidden Layers & $1-4$ (with 16, 13, 13 and 10 neurons/layer) \\
\hline Activation Functions & Tahn (ReLU and Linear only firstly tested) \\
\hline Learning Rate / Validation Split & $0.01-0.0001 / 0.30-0.40$ \\
\hline Train Loss / Metrics / Optimizer & MSE / MAE / RMSprop \\
\hline Epochs / Batch Size & $16-1600$ / 8 - 32 \\
\hline
\end{tabular}

To validate the information obtained from the MLP, the statistical metrics compare the results simulated by the ANN with the original timeseries from WRF output, adjusting it with a shift of one time-step ahead, to represent the same effect of predicting this variable one hour ahead. The dataset for training the network gets 
information from cells of D02 in perimeter closer to the 9 INMET stations, that are shown in Table 4. The grid-cells that match with the position of those stations have been reserved for the test dataset - so that the metrics based on WRF adjusted outputs share the same reference as the WRF real data simulation did during the previous validation process.

Table 4. INMET Stations over the D02 WRF Domain

\begin{tabular}{|c|c|c|c|c|}
\hline Index & INMET Station & Latitude & Longitude & $\begin{array}{l}\text { Sequenced } \\
\text { Samples ANN }\end{array}$ \\
\hline S01 & Castro & $24.7870 \mathrm{~S}$ & $49.9993 \mathrm{~W}$ & $0-1103$ \\
\hline S02 & Irati & $25.5028 \mathrm{~S}$ & $50.6376 \mathrm{~W}$ & $1104-2207$ \\
\hline S03 & Itapeva & $23.9819 \mathrm{~S}$ & $48.8858 \mathrm{~W}$ & $2208-3311$ \\
\hline S04 & Japira & $23.7733 \mathrm{~S}$ & 50.1806 W & $3312-4415$ \\
\hline S05 & Joaquim Távora & $23.5053 \mathrm{~S}$ & $49.9464 \mathrm{~W}$ & $4416-5519$ \\
\hline S06 & Londrina & $23.3256 \mathrm{~S}$ & $51.1417 \mathrm{~W}$ & $5520-6623$ \\
\hline S07 & Maringá & $23.4054 \mathrm{~S}$ & $51.9328 \mathrm{~W}$ & $6624-7727$ \\
\hline S08 & Presidente Prudente & $22.1199 \mathrm{~S}$ & $51.4086 \mathrm{~W}$ & $7728-8831$ \\
\hline S09 & Ventania & $24.2804 \mathrm{~S}$ & $50.2102 \mathrm{~W}$ & $8832-9935$ \\
\hline
\end{tabular}

\section{RESULTS AND DISCUSSION}

Since the first configuration set tested (simple 3-Layer ANN), the network has been able to reproduce the behavior of the wind speed average magnitude with reasonable precision. However, there were no statistically significant differences increasing the number of hidden layers as well as considering different number of epochs, batch sizes and learning rates - as initially pointed (in the methodology topic) on Table 3 and complemented on Table 5.

Table 5. Configuration Sets of Architecture and Metrics of Hybrid Model x WRF

\begin{tabular}{|l|c|c|c|c|c|c|c|c|}
\hline Archit. & Layer 2 & Layer 3 & Layer 4 & Layer 5 & MAE & MSE & $R^{2}$ & Pearson r \\
\hline Config. I & $16 \mathrm{n}$ & - & - & - & 0.4274 & 0.3873 & 0.7781 & 0.8821 \\
\hline Config. II & $13 \mathrm{n}$ & $10 \mathrm{n}$ & - & - & 0.4375 & 0.3923 & 0.7752 & 0.8826 \\
\hline Config. III & $13 \mathrm{n}$ & $13 \mathrm{n}$ & $10 \mathrm{n}$ & - & 0.4256 & 0.3894 & 0.7769 & 0.8824 \\
\hline Config. IV & $13 \mathrm{n}$ & $13 \mathrm{n}$ & $10 \mathrm{n}$ & $10 \mathrm{n}$ & 0.4312 & 0.3974 & 0.7723 & 0.8820 \\
\hline
\end{tabular}


A slight tendency of overestimation for extreme conditions has been recurrently noticed in the results, as one can see in Figure 2. Similar patterns and precision have been also obtained in literature [10] with MLP for wind speed prediction, using as data inputs information locally measured instead of GFS or WRF outputs (as defined in this work). More recently, recurrent and convolutional neural networks (instead of MLP) have been applied [14] to forecast, not wind speed, but another atmospheric variable: tropospheric ozone - showing similar accuracy as these results, for even longer timeranges (more time-steps ahead).

Figure 2. Hybrid Model Prediction (for $1 \mathrm{~h}$ ahead) $x$ Conventional WRF Real Data Simulation

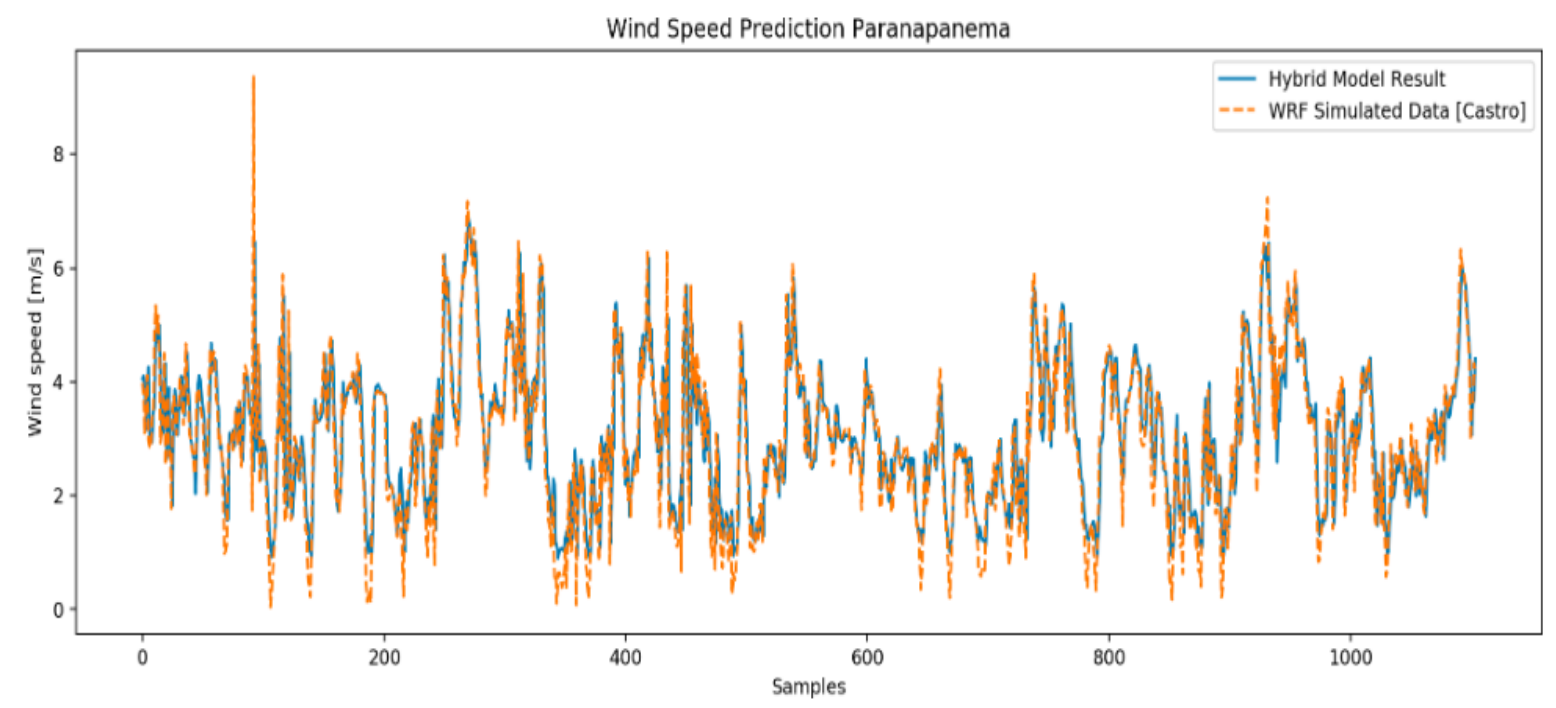

\section{CONCLUSION}

Although the approach tested in this paper considers a short-range target (one time-step ahead), it has shown effectiveness to emulate the wind speed behavior for the proposed locations (Table 4) never used to train the network, just using data from a previously executed WRF run. An enlargement of the prediction time range should be a suggestion for future works, as the similarity with the real data could also be optimized by demand [9] for the higher wind speed conditions. The combination of types of networks has been indicated [13] as an efficient way to optimize the fit performance. Other types of ANNs, more specialized for time series forecasting - like deep and recurrent neural networks [14] - can also be further investigated. Furthermore, a more robust and complete Al model can be developed in order to, based on this approach, predict other important meteorological parameters from WRF runs, such as air temperature, humidity, pressure, planetary boundary layer height, etc. 


\section{Acknowledgments}

The authors acknowledge CIMATEC's Supercomputing Center for Industrial Innovation (CS2i), Reference Center on Artificial Intelligence for computationaltechnical support and FAPESB (process number BOL2345/2019).

\section{REFERENCES}

${ }^{1}$ BARTHOLD L. et al. Improving flash flood forecasts: The HMT-WPC flash flood and intense rainfall experiment. Bull. Amer. Meteor. Soc., v. 96, p. 1859-1866, 2015.

2 S ARAÚJO, A. et al. Ciência, Tecnologia e Sociedade; Trabalho e Educação: possibilidades de integração no currículo da Educação Profissional Tecnológica. Rev. Ensaio Belo Horizonte, v. 14, n.1, p. 99-112, jan-abr, , 2012.

${ }^{3} \mathrm{PENG}, \mathrm{H}$ et al. A hybrid strategy of short-term wind power prediction Renewable Energy v. 50, p. 590-595, 2013.

${ }^{4}$ SKAMAROCK, W.C. et al. A Description of the Advanced Research WRF Version 3 (NCAR Technical Note), Mesoscale and Microscale Meteorology Division of NCAR. Boulder, Colorado, USA, 2008.

${ }^{5} \mathrm{KURTH}, \mathrm{T}$. et al. Exascale deep learning for climate analytics. In Proceedings of the international conference for high performance computing, networking, storage, and analysis, IEEE Press, Dallas, Texas, p. 51, 2018

${ }^{6}$ LAGERQUIST, R. et al. Deep learning for spatially explicit prediction of synoptic-scale fronts. Weather and Forecasting, v. 34, n. 4, p. 1137-1160, 2019.

7 CHENG, W.Y.Y. et al. Short-term wind forecast of a data assimilation/weather forecasting system with wind turbine anemometer measurement assimilation. Renewable Energy v. 107, p. 340-351, 2017.

${ }^{8}$ WASILEWSKIA, J. et al. Short-term electric energy production forecasting at wind power plants in pareto-optimality context. Renewable and Sustainable Energy Reviews v. 69, p. 177-187, 2017.

${ }^{9} \mathrm{LIU}, \mathrm{H}$ et al. Wind speed forecasting method based on deep learning strategy using empirical wavelet transform, long short-term memory neural network and Elman neural network. Energy Conversion and Management, v. 156, 15 January, p. 498-514, 2018

10 ZUCATELLI, P.J.et al. Short-term wind speed forecasting in Uruguay using computational intelligence. Heliyon, v. 5, Issue 5, May, e01664, 2019

${ }^{11} \mathrm{AKINCl}, \mathrm{T} . \mathrm{C}$. Short term wind speed forecasting with ANN in Batman, Turkey. Electron Electr Eng 1(107), p. 41-5., 2011

12 NOGAY, H.S., et al. Application of artificial neural networks for short term wind speed forecasting in Mardin, Turkey. J. energy South. Afr. 23(4), p. 2-7, 2012.

${ }^{13}$ OKUMUS, I. et al. Current status of wind energy forecasting and a hybrid method for hourly predictions. Energy Conversion and Management, v 123, p. 362-371, 2016.

14 JUNIOR, A. et al. Assessing Recurrent and Convolutional Neural Networks for Tropospheric Ozone Forecasting in The Region of Vitória, Brazil, Air Polution, June p. 101-112, 2020. 